\title{
KAJI EKSPERIMEN VARIASI JENIS SERAT BATANG PISANG UNTUK BAHAN KOMPOSIT TERHADAP KEKUATAN MEKANIK
}

\author{
Asroni $^{1}$, Sulis Dri Handono² \\ Jurusan Teknik Mesin, Fakultas Teknik, Universitas Muhammadiyah Metro \\ Jl. Ki Hajar Dewantara 15 A Metro, Lampung \\ Email: as.roni@aol.com¹, esdehaa@gmail.com²
}

\begin{abstract}
Abstrak
Komposit merupakan material yang terbentuk dari kombinasi dua atau lebih material, sehingga dihasilkan material yang mempunyai sifat mekanik dan karakteristik yang berbeda dari material pembentuknya. Bahan komposit memiliki banyak keunggulan diantaranya: berat jenisnya, kuat, tahan korosi, dan memiliki biaya pembuatan yang lebih murah. Bahan komposit terdiri dari dua jenis, yaitu bahan komposit partikel dan bahan komposit serat [1]. Batang pisang dari limbah perkebunan pisang dipotong dengan ukuran $25 \mathrm{~cm}$ supaya proses pengambilan serat yang lebih mudah. Batang pisang dijemur hingga kering sebelum diambil seratnya, hal ini dilakukan agar kadar air yang ada di batang pisang hilang dan supaya mudah pada saat pengambilan serat. Batang pisang disisir menggunakan sikat kawat untuk memisahkan antara serat dengan partikel partikel-partikel yang ada pada pelepah pisang. Serat yang sudah terpisah kemudian dijemur dalam waktu 2-3 hari, tetapi penjemuran dilakukan tanpa kontak langsung dengan sinar matahari. Nilai hasil uji rata-rata kekuatan tarik dari komposit serat batang pisang raja $\left(19,88 \mathrm{~N} / \mathrm{mm}^{2}\right)$, pisang kepok $\left(25,46 \mathrm{~N} / \mathrm{mm}^{2}\right)$, pisang raja sereh $\left(15,02 \mathrm{~N} / \mathrm{mm}^{2}\right)$ dan pisang jantan $\left(22,96 \mathrm{~N} / \mathrm{mm}^{2}\right)$. Dapat diketahui bahwa komposit serat batang kepok memiliki nilai kekuatan tarik yang paling besar dengan nilai hasil uji rata-rata $25,46 \mathrm{~N} / \mathrm{mm}^{2}$. Nilai hasil uji rata-rata kekerasan dari komposit serat batang pisang raja, pisang kepok, pisang raja sereh dan pisang jantan adalah 98,6 HRR; 83,4 HRR; 96,5 HRR; dan 101,75 HRR. Dapat diketahui bahwa komposit serat batang pisang jantan memiiki nilai kekerasan yang paling tinggi dengan nilai hasil uji rata-rata 98,6 HRR. Tinggi rendahya nilai hasil uji rata-rata kekerasan dan kekuatan tarik komposit serat batang pisang dapat dipengaruhi oleh besar kecilnya serat yang dimiliki oleh batang pisang, susunan serat, dan adanya void (kekosongan) pada masing-masing komposit serat batang pisang. Untuk pengujian tarik didapat nilai terbesar pada serat batang pisang kepok dengan nilai 25,46 $\mathrm{N} / \mathrm{mm}^{2}$. Kemudian untuk pengujian kekerasan didapat nilai pengujian terbesar pada jenis batang pisang jantan dengan nilai kekerasan 98,6 HRR
\end{abstract}

Kata kunci: Komposit, Serat, Batang Pisang, Kuat Tarik, Kekerasan.

\section{PENDAHULUAN}

Serat sacara umum terdiri dari dua jenis yaitu serat sintetis dan serat alam. Serat sintetis yaitu serat buatan dengan mengkombinasikan bahan-bahan kimia sehingga menghasilkan serat yang sesuai dengan kebutuhan, seperti contoh kaca, keramik, fiber glass dan lain-lain. Serat alami yaitu serat yang berasal dari tumbuh - tumbuhan yang ada disekitar kita, seperti contoh serat kulit kelapa dan serat pelepah kelapa sawit. Salah satu serat alam yang banyak terdapat di lingkungan sekitar adalah serat batang pisang, karena pemanfaatan batang pisang belum banyak yang mengolahnya dan hanya menjadi limbah maka penulis akan mengembangkan potensi alam ini menjadi sebuah bahan campuran pada komposit sebagai penguat, selain itu dapat meningkatkan nilai ekonomis dari limbah perkebunan pisang ini.

Matrik adalah bahan yang memberikan rupa bentuk dan memegang 
bahan pengukuh dalam komponen. juga Secara umum matrix jenis polimer terbagi menjadi 2 yaitu matrix jenis thermoplastik dan jenis thermoset. Thermoplastic adalah polimer yang bercabang menjadi keras apabila didinginkan, dan menjadi lunak bila dipanaskan. Thermoset merupakan bahan yang tidak boleh dibentuk ulang setelah struktu ahir dibuat. Keuntungan penggunaan bahan thermoset ialah mempunyai kesetabilan thermal yang tinggi, pengaruh terhadap perubahan bentuk dibawah tekanan dan kesetabilan dimensi yang tinggi dan kekerasan yang tinggi [2].

Pohon pisang memiliki ciri-ciri ujung daun yang berbentuk rompang dan daging daunnya yang sangat tipis. Pertulangannya daun berbentuk menyirip. Daun pisang ini berbentuk memanjang dan melebar berwarna hijau tua, tananam ini berakal serabut dan tidak memiliki akar tunggal bergerak menyamping sepanjang 45 meter. Sedangkan untuk batangnya dibedakan menjadi 2 macam yaiitu batang asli dan batang semu, batang asli ada di pangkal batang semu yang memiliki banyak mata tunas, tumbuhan pisang juga memiliki bunga, buah terdiri dari beberapa sisir yang tergantung. Untuk umur panen pohon pisang ini dari masa tanam sampai panen rata-rata 9-12 bulan. Pohon pisang mulai berbunga waktu umur 9 bulan dari waktu tanam setelah 3 bulan kemudian masuklah masa panen [3].

Melihat dari potensi tersedianya bahan baku, maka penelitian ini diarahkan untuk pemanfaatan serat batang pisang sebagai bahan penenguat komposit. Dari berbagai jenis pisang, akan diteliti jenis serat batang pisang kepok, raja sereh (susu), jantan, dan raja. Jenis batang pisang juga dibedakan dari perbedaan umur supaya bisa mengetahui seperti apa jenis serat pisang yang baik dan mempengarui kualitas atau tidak. dengan menggunakan penelitian uji tarik dan uji kekerasan.

\section{TINJAUAN PUSTAKA}

\section{Batang Pisang}

Pada umumnya batang pisang tumbuh lurus ke atas dan tidak bercabang. Setiap batang pisang hanya memiliki satu titik tumbuh yang terletak di ujung batang, yakni yang membentuk daun-daun dan batang. Batang pisang semu adalah batang yang terbentuk dari pelepah daun yang membesar di pangkalnya dan mengumpul membentuk struktur berselang-seling yang terlihat kompak sehingga nampak seperti batang. Sedangkan batang pisang yang asli berada di pangkal batang semu yang tenggelam di bawah permukaan tanah. Pada umumnya tinggi pohon pisang mencapai 35 meter, dengan garis tengah antara 70-80 $\mathrm{cm}$ tergantung pada keadaan iklim, tanah, dan lingkungan memiliki ukuran lingkar batang yang lebih besar dibandingkan dengan pisang yang ditanam pada tanah yang tidak subur. Batang pisang hanya berisi serabut-serabut yang lunak, sehingga tidak dapat digunakan sebagai bangunan dan lain - lain. Namun batang pisang dapat dimanfaatkan sebagai sayur.

$$
\text { Batang pisang banyak }
$$

dimanfaatkan masyarakat, terutama bagian yang mengandung serat. Setelah dikelupas setiap lembar sering dimanfaatkan sebagai pembungkus untuk bibit tanaman sayuran, dan setelah dikeringkan digunakan untuk tali pada pengolahan tembakau, dan dapat pula digunakan untuk kompos [4].

\section{Komposit}

Komposit didefinisikan sebagai kombinasi antara dua material atau lebih yang berbeda bentuknya, komposisi kimianya, dan tidak saling melarutkan antara materialnya dimana material yang satu berfungsi sebagai penguat dan material yang lainnya berfungsi sebagai pengikat untuk menjaga kesatuan unsur-unsurnya. Secara umum terdapat dua kategori material penyusun komposit yaitu matrik dan reinforcement [5].

Matriks dapat diklasifikasikan menjadi dua, yaitu termoplastik dan termoset. Beberapa jenis matrik polimer 
termoset yang sering digunakan ialah poliester, epoxy, phenolics, dan polyamids, sedangkan yang termasuk jenis matrik polimer termoplastik adalah polyethylene, polypropylene, nilon, polycarbonate, dan polyether-ether keton. Dalam penelitian ini matriks yang digunakan adalah resin poliester.

\section{Serat}

Serat atau fiber dalam bahan komposit berperan sebagai bagian utama yang menahan beban, sehingga besar kecilnya kekuatan bahan komposit sangat tergantung dari kekuatan serat pembentuknya. Serat terdiri dari dua jenis yaitu, serat alam dan serat sintetis. Serat alam adalah serat yang dapat langsung diperoleh dari alam. Biasanya berupa serat yang dapat langsung diperoleh dari tumbuh-tumbuhan dan binatang. Serat ini telah banyak digunakan oleh manusia diantaranya adalah kapas, wol, sutera, pelepah kelapa sawit, sabut kelapa, ijuk, bambu, nanas, dan knaf atau goni. Serat sintetis adalah serat yang dibuat dari bahanbahan anorganik dengan komposisi kimia tertentu. Serat sintetis yang telah banyak digunakan antara lain serat gelas, serat karbon, kevlar, nilon, dan lain-lain.

Serat alami merupakan serat yang mulai banyak digunakan saat ini. Hal ini tidak lain bertujuan untuk meningkatkan nilai suatu bahan,sedangkan bahan yang digunakan adalah limbah pertanian. Di samping itu demi kelestarian alam komposit ini mulai dikembangkan di berbagai bidang penelitian yang tak lain tujuannya adalah untuk meminimalkan pencemaran alam. Seperti yang kita ketahui selama bahan yang kita gunakan alami maka bahan ini tidak akan memberi efek pencemaran yang besar bagi alam karena sifat renewble-nya, yaitu dapat diperbaharui. Disamping kelebihannya pasti terdapat kekurangan pada bahan alam ini seperti kekuatan serat dan daya tahan pada benturan karena itu penelitian ini ditujukan untuk mengurangi kemungkinankemungkinan tersebut.
Serat sintetis atau serat buatan adalah serat yang berasal dari bahan-bahan anorganik yaitu bahan buatan yang berasal dari penggabungan bahan-bahan kimia, contohnya fiberglass. Serat ini berasal dari campuran bahan silikondioksida (SiO2) dan bahan oksida lain seperti Aluminium, Kalsium , Natrium , Magnesium, dan unsur oksida lainnya. Serat ini mempunyai kekuatan yang lebih dibanding serat alami, namun untuk nilai ekonomisnya sangat mahal untuk mendapatkan bahan-bahan tersebut.

Tabel 1. Sifat Mekanik dari Beberapa Jenis Serat [6]

\begin{tabular}{|l|l|r|r|r|r|r|r|}
\hline \multicolumn{2}{|l|}{} & $\begin{array}{r}\text { Cotto } \\
\mathbf{n}\end{array}$ & Flax & $\begin{array}{c}\text { Jut } \\
\mathbf{e}\end{array}$ & $\begin{array}{c}\text { Kena } \\
\mathbf{f}\end{array}$ & $\begin{array}{c}\text { Rami } \\
\mathbf{e}\end{array}$ & $\begin{array}{c}\text { Sisa } \\
\mathbf{1}\end{array}$ \\
\hline Diameter & $\mathrm{mm}$ & - & $\begin{array}{r}11- \\
33\end{array}$ & 200 & 200 & $40-80$ & $\begin{array}{r}50- \\
200\end{array}$ \\
\hline Panjang & $\mathrm{mm}$ & $10-60$ & $\begin{array}{r}10- \\
40\end{array}$ & $1-5$ & $2-6$ & $\begin{array}{r}60- \\
260\end{array}$ & $1-5$ \\
\hline $\begin{array}{l}\text { Kekuatan } \\
\text { tarik }\end{array}$ & $\mathrm{Mpa}$ & $\begin{array}{r}330- \\
585\end{array}$ & $\begin{array}{r}345- \\
103 \\
5\end{array}$ & $\begin{array}{r}393 \\
773\end{array}$ & 930 & $\begin{array}{r}400- \\
1050\end{array}$ & $\begin{array}{r}511- \\
635\end{array}$ \\
\hline $\begin{array}{l}\text { Modulus } \\
\text { elastisitas }\end{array}$ & $\mathrm{Gpa}$ & $\begin{array}{r}4,5- \\
12,6\end{array}$ & $\begin{array}{r}27,6 \\
45,0\end{array}$ & $\begin{array}{r}26, \\
5\end{array}$ & 53,0 & 61,5 & $\begin{array}{r}9,4- \\
15,8\end{array}$ \\
\hline $\begin{array}{l}\text { Massa } \\
\text { jenis }\end{array}$ & $\mathrm{g} / \mathrm{cm} \mathrm{m}^{2}$ & $\begin{array}{r}1,5- \\
1,54\end{array}$ & $\begin{array}{r}1,43 \\
1,52\end{array}$ & $\begin{array}{r}144 \\
1,5 \\
0\end{array}$ & 1,5 & $\begin{array}{r}1,5- \\
1,6\end{array}$ & $\begin{array}{r}1,16 \\
-1,5\end{array}$ \\
\hline $\begin{array}{l}\text { Regangan } \\
\text { maksimu } \\
\mathrm{m}\end{array}$ & $\%$ & $\begin{array}{r}7,0- \\
8,0\end{array}$ & $\begin{array}{r}2,7- \\
3,2\end{array}$ & $\begin{array}{r}1,5- \\
1,8\end{array}$ & 1,6 & $\begin{array}{r}3,6- \\
3,8\end{array}$ & $\begin{array}{r}2,0- \\
2,5\end{array}$ \\
\hline $\begin{array}{l}\text { Spesifik } \\
\text { kekuatan } \\
\text { tarik }\end{array}$ & $\mathrm{Km}$ & 39,2 & 73,8 & $\begin{array}{r}52, \\
5\end{array}$ & 63,2 & 71,4 & 43,2 \\
\hline $\begin{array}{l}\text { Spesifik } \\
\text { kekuatan }\end{array}$ & $\mathrm{Km}$ & 0,85 & 3,21 & $\begin{array}{r}1,8 \\
0\end{array}$ & 3,60 & 4,18 & 1,07 \\
\hline
\end{tabular}

\section{Pengujian Tarik}

Uji tarik merupakan pengujian yang bertujuan untuk mengetahui kekuatan suatu bahan berdasarkan ketahanan suatu material terhadap beban tarik yang diberikan secara aksial. Dalam pengujian, spesimen uji dibebani dengan kenaikan beban perlahan-lahan hingga spesimen uji tersebut patah. Pengujian tarik yang dilakukan suatu material padatan (logam dan non logam) dapat memberikan keterangan yang relatif lengkap mengenai perilaku material tersebut terhadap pembebanan mekanis. informasi penting yang bisa didapat adalah :

1. Batas Proposionalitas

(Proponalionnality Limit)

Merupakan daerah batasan dimana tegangan dan regangan mempunyai hubungan proporsionalitas satu dengan 
yang lain. Setiap penambahan tegangan akan diikuti dengan penambahan regangan secara proporsional dalam hubungan linier.

\section{Batas Elastis (Elastic Limit)}

Daerah elastis adalah daerah dimana bahan akan kembali kepada panjang semula bila tegangan luar dihilangkan. Daerah proporsionalitas merupakan bagian dari batas elastis ini. Selanjutnya bila bahan terus diberikan tegangan (deformasi dari luar) maka batas elastis akan terlampaui pada akhirnya sehingga bahan tidak akan kembali kepada ukuran semula. Dengan kata lain dapat didefinisikan bahwa batas elastis merupakan suatu titik dimana tegangan yang diberikan akan menyebabkan terjadinya deformasi permanen (plastis) pertama kalinya. Kebanyakan material teknik memiliki batas elastis yang hampir berimpitan dengan batas proporsionalitasnya.

3. Titik Luluh (Yield Point) dan Kekuatan Luluh (Yield Strength)

Titik ini merupakan suatu batasan dimana material akan terus mengalami deformasi tanpa adanya penambahan beban. Tegangan (stress) yang mengakibatkan bahan menunjukkan mekanisme luluh disebut tegangan luluh (yield stress).

\section{Kekuatan Putus (Breaking Strength)}

Kekuatan putus ditentukan dengan membagi beban pada saat benda uji putus (breaking) dengan luas penampang awal Ao. Untuk bahan yang bersifat ulet pada saat beban maksimum $\mathrm{M}$ terlampaui dan bahan terus terdeformasi hingga titik putus B maka terjadi mekanis ciutan (necking) sebagai akibat adanya suatu deformasi yang terlokalisasi. Pada bahan ulet kekuatan putus adalah lebih kecil dari pada kekuatan maksimum sementara pada bahan getas kekuatan putus adalah sama dengan kekuatan maksimumnya.

\section{Keuletan (Ductility)}

Keuletan merupakan suatu sifat yang menggambarkan kemampuan logam menahan deformasi hingga terjadinya perpatahan. Sifat ini, dalam beberapa tingkatan, harus dimiliki oleh bahan bila ingin di bentuk (forming) melalui proses rolling, bending, stretching, drawing, hammering, cutting dan sebagainya. Pengujian tarik memberikan dua metode pengukuran keuletan bahan yaitu:

1) Persentase perpanjangan (Elongation) Diukur sebagai penambahan panjang ukur setelah perpatahan terhadap panjang awalnya.

2) Persentase pengurangan atau reduksi penampang (Area Reduction).

Diukur sebagai pengurangan luas penampang (cross-section) setelah perpatahan terhadap luas penampang awalnya.

6. Modulus Elastisitas (E)

Modulus elastisitas atau Modulus

Young merupakan ukuran kekakuan suatu material. Semakin besar harga modulus ini maka semakin kecil regangan elastis yang terjadi pada suatu tingkat pembebanan tertentu, atau dapat dikatakan material tersebut semakin kaku (stiff), Dapat dihitung dari grafik tegangan-regangan.

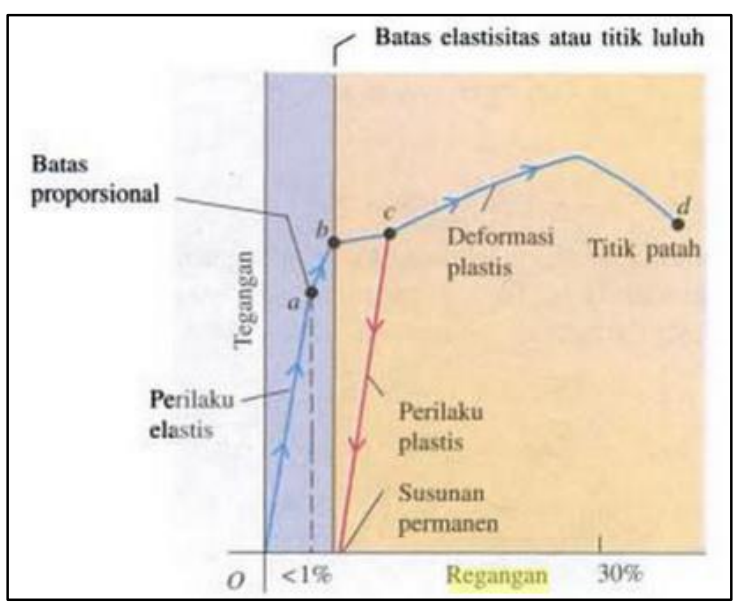

Gambar 1. Diagram Tegangan Regangan

[7]

\section{METODE PENELITIAN}

\section{Tahapan-tahapan Penelitian}

1. Pengambilan serat dari batang pisang

1) Batang pisang dari limbah perkebunan pisang dipotong dengan ukuran $25 \mathrm{~cm}$ supaya proses 
pengambilan serat yang lebih mudah,

2) Batang pisang dijemur hingga kering sebelum diambil seratnya, hal ini dilakukan agar kadar air yang ada di batang pisang hilang dan supaya mudah pada saat pengambilan serat,

3) Batang pisang disisir menggunakan sikat kawat untuk memisahkan antara serat dengan partikel partikel-partikel yang ada pada pelepah pisang,

4) Serat yang sudah terpisah kemudian dijemur dalam waktu 2-3 hari, tetapi penjemuran dilakukan tanpa kontak langsung dengan sinar matahari.

2. Pembuatan Cetakan Spesimen

Bahan yang digunakan untuk cetakan ini adalah plat besi. Hal ini dikarenakan hasil cetakan lebih mudah dalam pelepasan. Spesimen uji dbuat satu persatu sebanyak 24 buah dengan perincian 12 buah untuk uji tarik dan 12 buah untuk uji kekerasan. Adapun standar pengujian yang dilakukan adalah ASTM dengan rincian sebagai berikut:

1. Uji tarik menggukan standar ASTM D $638-03$

2. Uji kekerasan mengunakan standar ASTM 758 - 03

Agar tidak terjadi kesalahan dalam pembuatan benda uji, maka ukuran cetakan dibuat sedikit lebih besar yaitu 1-5 mm.

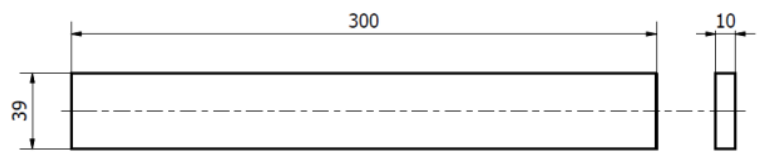

Gambar 2. Cetakan Spesimen Uji Tarik ASTM D 638-03

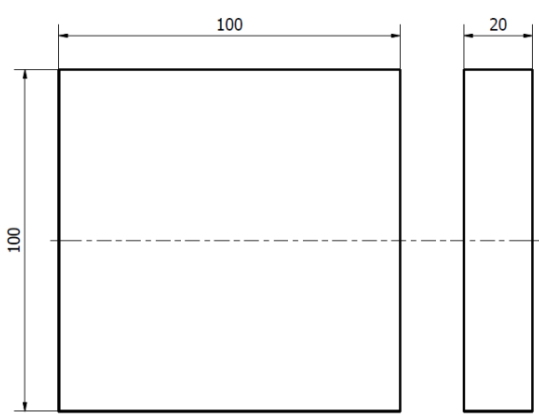

Gambar 3. Cetakan Spesimen Uji Kekerasan ASTM D 785-03
3. Proses Pembuatan Komposit

Proses pembuatan komposit serat dari pelepah batang pisang dengan matrik polyester adalah sebagai berikut:

1) Serat yang sudah diekstrat, kemudian direndam dan dicuci dari kotoran dengan air. Serat diangin-anginkan sampai kering ditempat teduh. Serat yang sudah dibersihkan dari kotoran kemudian direndam larutan alkali $\mathrm{NaOH}$ selama 2 jam. Serat kemudian dibilas dengan air bersih, kemudian serat dikeringkan di tempat yang tidak terkena sinar mata hari langsung.

2) Cetakan dibersihkan, kemudian dioleskan wak atau oli secara merata agar komposit tidak menempel pada cetakan.

3) Membuat campuran resin dengan katalis dengan perbandingan 99:1, kemudian diaduk hingga merata selama 4 menit.

4) Masukkan serat batang pohon pisang kedalam cetakan, kemudian tuang resin hingga penuh sambil ditekan-tekan untuk menghindari terjadinya gelembung udara.

5) Pasang tutup cetakan agar permukaan komposit menjadi rata, kemudian diberi beban diatasnya.

6) Biarkan hingga mengering selama 2 jam, kemudian komposit dikeluarkan dari cetakan.

7) Benda uji komposit siap untuk dipotong menjadi spesimen benda uji.

8) Lakukan langkah-langkah diatas untuk setiap serat batang pohon pisang yang akan digunakan untuk pengujian.

Tabel 2. Jumlah Spesimen Uji

\begin{tabular}{|c|c|c|l|l|c|}
\hline \multirow{2}{*}{ NO } & \multirow{2}{*}{$\begin{array}{l}\text { Jenis } \\
\text { Pengujian }\end{array}$} & $\begin{array}{l}\text { Jenis Serat Batang Pisang } \\
\text { batang } \\
\text { pisang } \\
\text { Kepok }\end{array}$ & $\begin{array}{l}\text { Serat } \\
\text { Batang } \\
\text { Pisang } \\
\text { Jantan }\end{array}$ & $\begin{array}{l}\text { Serat } \\
\text { Batang } \\
\text { Pisang } \\
\text { Raja }\end{array}$ & $\begin{array}{l}\text { Serat } \\
\text { Batang } \\
\text { Pisang } \\
\text { Raja } \\
\text { sereh }\end{array}$ \\
\hline 1 & Uji Tarik & 3 & 3 & 3 & 3 \\
\hline 2 & $\begin{array}{l}\text { Uji } \\
\text { Kekerasan }\end{array}$ & 3 & 3 & 3 & 3 \\
\hline \multicolumn{2}{|c|}{ Jumlah } & 6 & 6 & 6 & 6 \\
\hline
\end{tabular}




\section{Waktu dan Tempat Penelitian}

Waktu pelaksanaan penelitian dimulai bulan Maret tahun 2018 sampai dengan Oktober tahun 2018. Penelitian ini dilakukan di Laboratorium Fakultas Teknik Mesin Universitas Muhamadiyah Metro.

\section{Pengujian}

Pelaksanan untuk masing-masing jenis pengujian adalah sebagai berikut:

1. Uji Tarik

Benda uji dijepit pada mesin uji kemudian beban statik diberikan secara bertahap sampai benda uji putus, dari pengujian ini diperoleh tegangan luluh. Sebelum pengujian diukur panjang mulamula dan setelah pengujian diukur pertambahan panjang benda uji setelah putus, untuk mengetahui berapa persentase elongation bahan.

2. Uji Kekerasan

Kekerasan merupakan kemampuan suatu material untuk bertaban dari proses abrasi (gesekan) atau takanan kedalam (idensitasi) oleh benda keras lain dengan cara menekankan benda yang keras kepada spesimen menggunakan beban standar, dan besar dari indentasi (baik itu area ataupun kedalaman) digunakan sebagai ukuran kekerasan material tersebut.

\section{HASIL DAN PEMBAHASAN}

Setelah melakukan uji kekerasan dan uji tarik, didapat hasil sebagai berikut:

\section{Uji Kekerasan}

Tabel 3. Hasil pengujian kekerasan komposit serat batang Pisang Raja

\begin{tabular}{|c|c|c|c|c|}
\hline No & $\begin{array}{c}\text { Parameter } \\
\text { uji }\end{array}$ & $\begin{array}{c}\text { Metode } \\
\text { uji } \\
\text { ASTM }\end{array}$ & $\begin{array}{c}\text { Hasil } \\
\text { Uji }\end{array}$ & Satuan \\
\hline 1. & \multirow{5}{*}{$\begin{array}{l}\text { Kekerasan } \\
\text { (Hardness) }\end{array}$} & \multirow{5}{*}{ D 785} & 113 & \multirow{6}{*}{ HRB } \\
\hline 2. & & & 101,75 & \\
\hline 3. & & & 91,5 & \\
\hline 4. & & & 96,5 & \\
\hline 5. & & & 90,25 & \\
\hline \multicolumn{3}{|c|}{ Rata-rata } & 98,6 & \\
\hline
\end{tabular}

Tabel 4. Hasil pengujian kekerasan dengan komposit serat batang Pisang Kepok

\begin{tabular}{|c|c|c|c|c|}
\hline No & $\begin{array}{c}\text { Parameter } \\
\text { Uji }\end{array}$ & $\begin{array}{c}\text { Metode } \\
\text { Uji } \\
\text { ASTM }\end{array}$ & $\begin{array}{c}\text { Hasil } \\
\text { Uji }\end{array}$ & Satuan \\
\hline 1. & \multirow{5}{*}{$\begin{array}{l}\text { Kekerasan } \\
\text { (Hardness) }\end{array}$} & \multirow{5}{*}{ D 785} & 82,25 & \multirow{6}{*}{ HRB } \\
\hline 2. & & & 92 & \\
\hline 3. & & & 92,5 & \\
\hline 4. & & & 71,25 & \\
\hline 5. & & & 79 & \\
\hline \multicolumn{3}{|c|}{ Rata-rata } & 83,4 & \\
\hline
\end{tabular}

Tabel 5. Hasil pengujian kekerasan dengan komposit serat batang pisang Raja Sereh

\begin{tabular}{|c|c|c|c|c|}
\hline No & $\begin{array}{c}\text { Parameter } \\
\text { Uji }\end{array}$ & $\begin{array}{c}\text { Metode } \\
\text { Uji } \\
\text { ASTM }\end{array}$ & $\begin{array}{c}\text { Hasil } \\
\text { Uji }\end{array}$ & Satuan \\
\hline 1. & \multirow{5}{*}{$\begin{array}{l}\text { Kekerasan } \\
\text { (Hardness) }\end{array}$} & \multirow{5}{*}{ D 785} & 109,75 & \multirow{6}{*}{ HRB } \\
\hline 2. & & & 106 & \\
\hline 3. & & & 69,5 & \\
\hline 4. & & & 113,5 & \\
\hline 5. & & & 83,75 & \\
\hline \multicolumn{3}{|c|}{ Rata-rata } & 96,5 & \\
\hline
\end{tabular}

Tabel 6. Hasil pengujian kekerasan dengan komposit serat batang Pisang Jantan

\begin{tabular}{|c|c|c|c|c|}
\hline No & $\begin{array}{c}\text { Parameter } \\
\text { Uji }\end{array}$ & $\begin{array}{c}\text { Metode } \\
\text { Uji } \\
\text { ASTM }\end{array}$ & $\begin{array}{c}\text { Hasil } \\
\text { Ujii }\end{array}$ & Satuan \\
\hline 1. & \multirow{5}{*}{$\begin{array}{l}\text { Kekerasan } \\
\text { (Hardness) }\end{array}$} & \multirow{5}{*}{ D 785} & 119,75 & \multirow{6}{*}{ HRB } \\
\hline 2. & & & 106,5 & \\
\hline 3. & & & 108 & \\
\hline 4. & & & 74,75 & \\
\hline 5. & & & 99,75 & \\
\hline \multicolumn{3}{|c|}{ Rata-rata } & 101,75 & \\
\hline
\end{tabular}




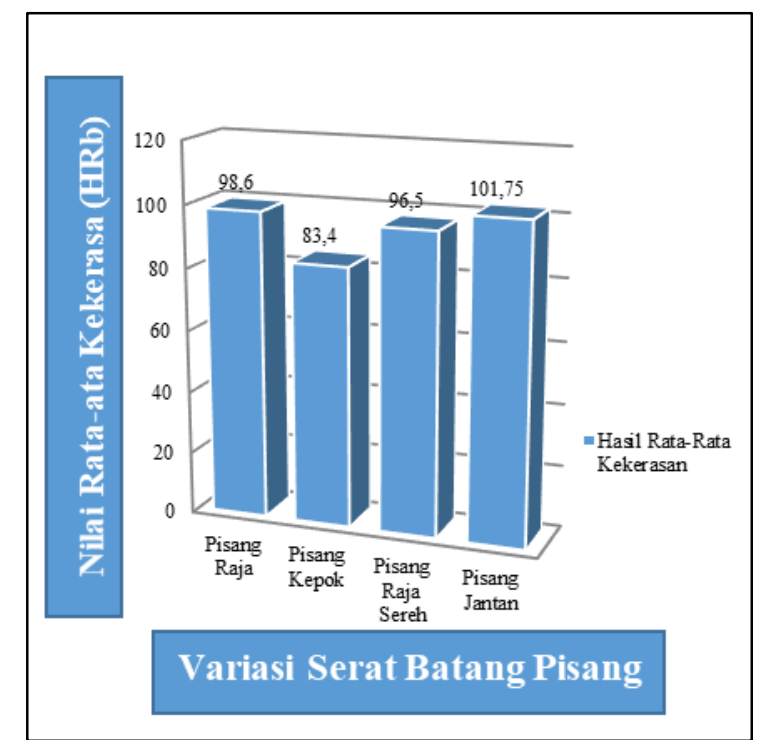

Gambar 4. Diagram Perbandingan Uji

Kekerasan Komposit dengan Variasi

Serat Batang Pisang

Tingginya nilai uji rata-rata kekerasan serat batang pisang jantan dibandingkan dengan komposit serat batang pisang yang lain dapat dipengaruhi karena adanya perbedaan serat dari keempat jenis batang pisang tersebut. Dalam hal ini serat batang pisang jantan memiliki kekerasan yang paling kuat karena seratnya yang kecil dibanding serat batang pisang yang lain sehingga memiliki daya tekan yang lebih besar. Sedangkan adanya penurunan nilai uji rata-rata kekerasan pada komposit serat batang pisang raja, raja sereh dan kepok dapat disebabkan karena tidak meratanya susunan serat dan adanya void (kekosongan) pada komposit serat batang pisang.

Tabel 7. Hasil pengujian tarik dengan komposit serat batang Pisang Raja

\begin{tabular}{|c|c|c|c|c|}
\hline No & $\begin{array}{c}\text { Parameter } \\
\text { Uji }\end{array}$ & $\begin{array}{c}\text { Metode } \\
\text { Uji } \\
\text { ASTM }\end{array}$ & $\begin{array}{c}\text { Hasil } \\
\text { Uji }\end{array}$ & Satuan \\
\hline 1. & \multirow{5}{*}{$\begin{array}{l}\text { Kuat tarik } \\
\text { (Tensile } \\
\text { strength) }\end{array}$} & \multirow{5}{*}{ D 638} & 17,56 & \multirow{6}{*}{$\mathrm{N} / \mathrm{mm}^{2}$} \\
\hline 2. & & & 20,26 & \\
\hline 3. & & & 18,97 & \\
\hline 4. & & & 24,08 & \\
\hline 5. & & & 18,51 & \\
\hline \multicolumn{3}{|c|}{ Rata-rata } & 19,88 & \\
\hline
\end{tabular}

Tabel 8. Hasil pengujian tarik dengan komposit serat batang Pisang Kepok

\begin{tabular}{|c|c|c|c|c|}
\hline No & $\begin{array}{c}\text { Parameter } \\
\text { Uji }\end{array}$ & $\begin{array}{c}\text { Metode } \\
\text { Uji } \\
\text { ASTM }\end{array}$ & $\begin{array}{c}\text { Hasil } \\
\text { Uji }\end{array}$ & Satuan \\
\hline 1. & \multirow{5}{*}{$\begin{array}{l}\text { Kuat tarik } \\
\text { (Tensile } \\
\text { strength) }\end{array}$} & \multirow{5}{*}{ D 638} & 45,30 & \multirow{6}{*}{$\mathrm{N} / \mathrm{mm}^{2}$} \\
\hline 2. & & & 30,58 & \\
\hline 3. & & & 18,32 & \\
\hline 4. & & & 18,13 & \\
\hline 5. & & & 14,96 & \\
\hline \multicolumn{3}{|c|}{ Rata-rata } & 25,46 & \\
\hline
\end{tabular}

Tabel 9. Hasil pengujian tarik dengan komposit serat batang pisang Raja Sereh

\begin{tabular}{|c|c|c|c|c|}
\hline No & $\begin{array}{c}\text { Parameter } \\
\text { Uji }\end{array}$ & $\begin{array}{c}\text { Metode } \\
\text { Uji } \\
\text { ASTM }\end{array}$ & $\begin{array}{c}\text { Hasil } \\
\text { Uji }\end{array}$ & Satuan \\
\hline 1. & \multirow{5}{*}{$\begin{array}{l}\text { Kuat tarik } \\
\text { (Tensile } \\
\text { strength) }\end{array}$} & \multirow{5}{*}{ D 638} & 11,81 & \multirow{6}{*}{$\mathrm{N} / \mathrm{mm}^{2}$} \\
\hline 2. & & & 12,01 & \\
\hline 3. & & & 24,99 & \\
\hline 4. & & & 12,89 & \\
\hline 5. & & & 13,40 & \\
\hline \multicolumn{3}{|c|}{ Rata-rata } & 15,02 & \\
\hline
\end{tabular}

Tabel 10. Hasil pengujian tarik dengan komposit serat batang Pisang Jantan

\begin{tabular}{|c|c|c|c|c|}
\hline No & $\begin{array}{c}\text { Parameter } \\
\text { Uji }\end{array}$ & $\begin{array}{c}\text { Metode } \\
\text { Uji } \\
\text { ASTM }\end{array}$ & $\begin{array}{c}\text { Hasil } \\
\text { Uji }\end{array}$ & Satuan \\
\hline 1. & \multirow{5}{*}{$\begin{array}{l}\text { Kuat tarik } \\
\text { (Tensile } \\
\text { strength) }\end{array}$} & \multirow{5}{*}{ D 638} & 16,73 & \multirow{6}{*}{$\mathrm{N} / \mathrm{mm}^{2}$} \\
\hline 2. & & & 27,68 & \\
\hline 3. & & & 23,82 & \\
\hline 4. & & & 25,24 & \\
\hline 5 . & & & 21,32 & \\
\hline \multicolumn{3}{|c|}{ Rata-rata } & 22,96 & \\
\hline
\end{tabular}

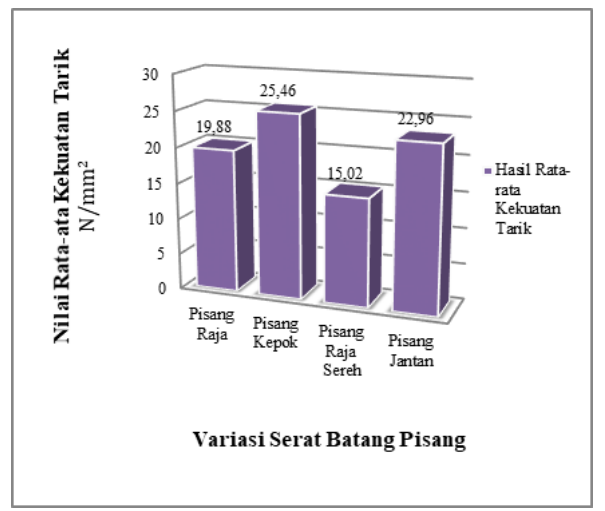

Gambar 5. Diagram Perbandingan

Kekuatan Tarik Komposit dengan

Variasi Serat Batang Pisang 
Dari hasil kekuatan tarik material komposit serat batang pisang yang diperoleh dari penelitian ini, dapat dilihat bahwa pisang kepok memiliki nilai kuat tarik yang paling besar yaitu $25,46 \mathrm{~N} / \mathrm{mm}^{2}$ disusul dengan pisang Jantan 22,96 N/mm ${ }^{2}$ dan pisang Raja 19,88 N/mm ${ }^{2}$ sedangkan pisang raja sereh memiliki kuat tarik paling rendah yaitu $15,02 \mathrm{~N} / \mathrm{mm}^{2}$. Tingginya kuat tarik serat batang pisang kepok dikarenakan besarnya serat yang dimiliki oleh batang pisang, sehingga komposit serat batang pisang kepok memiliki daya ikat yang lebih besar ketika dilakukan pengujian tarik.

Serat batang pisang kepok memiliki kekuatan tarik yang besar dikarenakan memiliki ukuran serat yang paling besar diantara keempat jenis serat batang pisang sehingga serat batang pisang kepok memiliki kekuatan tarik yang paling besar. Sedangkan pada uji kekerasan memilki nilai yang kecil dalam satu spesimen menjadi sedikit. Hal ini membuat spesimen menjadi lebih lemah pada saat dilakukan pengujian kekerasan.

Serat batang pisang jantan memiliki kekuatan tarik yang rendah karena serabut serat yang tipis membuat spesimen lebih lemah saat dilakukan pengujian tarik. Sedangkan pada uji kekerasan memiliki nilai yang paling besar karena serat batang yang tipis membuat jumlah serat dalam satu spesimen menjadi lebih banyak. Jumlah serat yang banyak ini menjadikan spesimen memiliki daya tekan yang lebih besar saat dilakukan pengujian.

\section{KESIMPULAN}

Dari hasil penelitian komposit serat batang pisang maka dapat diambil kesimpulan bahwa:

1. Nilai hasil uji rata-rata kekuatan tarik dari komposit serat batang pisang raja $\left(19,88 \mathrm{~N} / \mathrm{mm}^{2}\right)$, pisang kepok $(25,46$ $\left.\mathrm{N} / \mathrm{mm}^{2}\right)$, pisang raja sereh $(15,02$ $\left.\mathrm{N} / \mathrm{mm}^{2}\right)$ dan pisang jantan $(22,96$ $\mathrm{N} / \mathrm{mm}^{2}$ ). Dapat diketahui bahwa komposit serat batang kepok memiliki nilai kekuatan tarik yang paling besar dengan nilai hasil uji rata-rata $25,46 \mathrm{~N} / \mathrm{mm}^{2}$.

2. Nilai hasil uji rata-rata kekerasan dari komposit serat batang pisang raja, pisang kepok, pisang raja sereh dan pisang jantan adalah 98,6 HRR; 83,4 HRR; 96,5 HRR; dan 101,75 HRR. Dapat diketahui bahwa komposit serat batang pisang jantan memiiki nilai kekerasan yang paling tinggi dengan nilai hasil uji rata-rata 98,6 HRR.

3. Tinggi rendahya nilai hasil uji ratarata kekerasan dan kekuatan tarik komposit serat batang pisang dapat dipengaruhi oleh besar kecilnya serat yang dimiliki oleh batang pisang, susunan serat dan adanya void (kekosongan) pada masing-masing komposit serat batang pisang. Untuk pengujian tarik didapat nilai terbesar pada serat batang pisang kepok dengan nilai $25,46 \mathrm{~N} / \mathrm{mm}^{2}$. Kemudian untuk pengujian kekerasan didapat nilai pengujian terbesar pada jenis batang pisang jantan dengan nilai kekerasan 98,6 HRR

\section{REFERENSI}

[1]. Hartono. (2016). Pengenalan Teknik Komposit. Yogyakarta: Deepublish.

[2]. Khotimah (2014). Komposit Serat Batang Pisang (SBP) Epoksi Sebagai Bahan Penyerap Bunyi. Natural, 322-326.

[3]. Nopriantina (2013). Pengaruh Ketebalan Serat Pelepah Pisang Kepok (Musa paradisiaca) Terhadap Sifat Mekanik Material Komposit Poliester-Serat. Jurnal Fisika Unand, 195-203.

[4]. Kaleka, N. (2013). Pisang-Pisang Komersial. Yogyakarta: ARCITA.

[5]. Maryanti, B. (2011). Pengaruh Alkalisasi Komposit Serat Kelapa-Poliester Terhadap 
Kekuatan Tarik. Jurnal

Rekayasa Mesin, 123-129.

[6]. Müller, D. K. (2003). New Discovery In The Properties Of Composites Reinforced With Natural Fibers. Journal Of Industrial Textiles.

[7]. Young, H. D. (2002). Fisika Universitas $\mathrm{Jl}$. 1/10. Jakarta:

Penerbit Erlangga. 